\title{
Deterministic and probabilistic seismic hazard analyses in Thailand and adjacent areas using active fault data
}

\author{
Santi Pailoplee ${ }^{1}$, Yuichi Sugiyama ${ }^{2}$, and Punya Charusiri ${ }^{1}$ \\ ${ }^{1}$ Earthquake and Tectonic Geology Research Unit (EATGRU), clo Department of Geology, Faculty of Science, \\ Chulalongkorn University, Bangkok 10330, Thailand \\ ${ }^{2}$ Active Fault Research Center, National Institute of Advanced Industrial Science and Technology (AIST) 7, \\ 1-1-1 Higashi, Tsukuba, Ibaraki 305-8567, Japan
}

(Received July 15, 2008; Revised July 14, 2009; Accepted August 10, 2009; Online published January 18, 2010)

\begin{abstract}
Seismic hazards in Thailand and adjacent areas were analyzed mainly on the basis of geological fault data. We identified 55 active fault zones using remote-sensing data on earthquake source parameters derived from both active fault data and earthquake catalogues. We selected strong ground-motion attenuation models by comparing the application of several candidate models with strong ground-motion data recorded in Thailand. Both deterministic (DSHA) and probabilistic (PSHA) approaches were used-DSHA for the design of critical construction and PSHA for the design of non-critical construction. We also applied two frequency-magnitude models in the PSHA approach: the exponential magnitude distribution model and the characteristic earthquake model. The seismic hazard results obtained using the deterministic and probabilistic approaches are not equivalent. The resulting DSHA map reveals extremely high seismic hazard levels in some areas of Thailand and in surrounding countries, while the PSHA map reveals a seismic hazard distribution similar to that of the DSHA but with lower seismic hazard levels. The areas of high seismic hazard include countries neighboring Thailand, such as Myanmar, Laos, Vietnam, and Indonesia (Sumatra Island), and areas within Thailand itself, primarily those areas in northern, western, and southern Thailand that are dominated by active fault zones.
\end{abstract}

Key words: Seismic hazard analysis, deterministic method, probabilistic method, active fault, Thailand.

\section{Introduction}

There are a number of active fault systems in northern, western, and southern Thailand (e.g., Fenton et al., 2003; Charusiri et al., 2004; Wong et al., 2005) (Fig. 1(a)). Thailand is also surrounded by other major earthquake sources, such as the great strike-slip Sagiang fault of central Myanmar (Bertrand and Rangin, 2003), a complex shear zone near the Laos-southwestern China border (Socquet and Pubellier, 2005), and the well-known Andaman subduction zone where the moment magnitude $\left(M_{\mathrm{w}}\right)$ 9.0 Sumatra-Andaman earthquake occurred on $26 \mathrm{De}-$ cember 2004 (Petersen et al., 2004). Instrumental earthquake records and historical earthquake information, including paleoseismological evidence (e.g., Fenton et al., 2003; Charusiri et al., 2004), all indicate that Thailand is an earthquake-prone area that should make provisions to mitigate potential seismic hazards.

In recent times, there have been few seismic hazard investigations that have focused on Thailand. Warnitchai and Lisantono (1996) and Palasri (2006) used the probabilistic approach to seismic hazard analysis by using recent seismicity data (i.e., from earthquake catalogues). Their results, however, may be characterized by a number of limitations because of the short history of instrumental recordings of

Copyright (c) The Society of Geomagnetism and Earth, Planetary and Space Sciences (SGEPSS); The Seismological Society of Japan; The Volcanological Society of Japan; The Geodetic Society of Japan; The Japanese Society for Planetary Sciences; TERRAPUB earthquakes. Because the recurrence interval of large earthquakes can be several hundreds to thousands of years, the time span covered by instrumental records is too short to represent the behavior of earthquake activity either along individual faults or in specific regions. It is currently accepted worldwide that paleoseismological information (i.e., active fault data) is important for evaluating seismic hazards (e.g., Atakan et al., 2001; Gurpinar, 2005). This information, which is obtained from active fault investigations, can bridge the gap between instrumental and pre-instrumental data. Petersen et al. (2007) calculated the probabilistic seismic hazard in Southeast Asia (including Thailand and adjacent areas) using both paleoseismological and seismicity data. However, they used the data from only 15 fault zones in Thailand and two fault zones from neighboring countries (i.e., the Sagiang fault zone in central Myanmar and the Red River fault zone in northern Vietnam) to evaluate the earthquake sources. This apparent disregard of the earthquake source (i.e., active faults) may result in less accurate seismic hazard maps in terms of the number of earthquake source zones. Changes in how we regard earthquake sources, therefore, should be made in order to eliminate artifacts on seismic hazard maps.

Here, we first provide some background on the use of active fault data for analyzing seismic hazards in Thailand and neighboring areas. Due to the insufficiency of paleoseismological data along the fault segments, we adopted the strategy of treating each site-specific paleoseismological study equally for individual fault zones with the aim of analyz- 
(a)

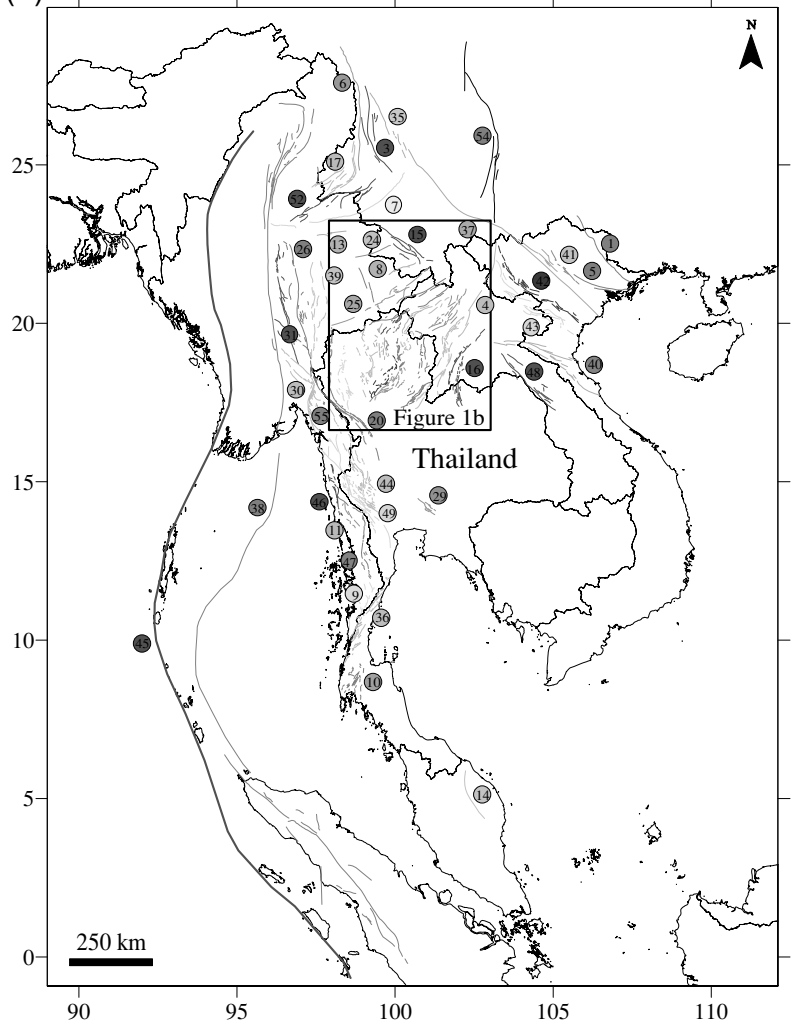

(b)

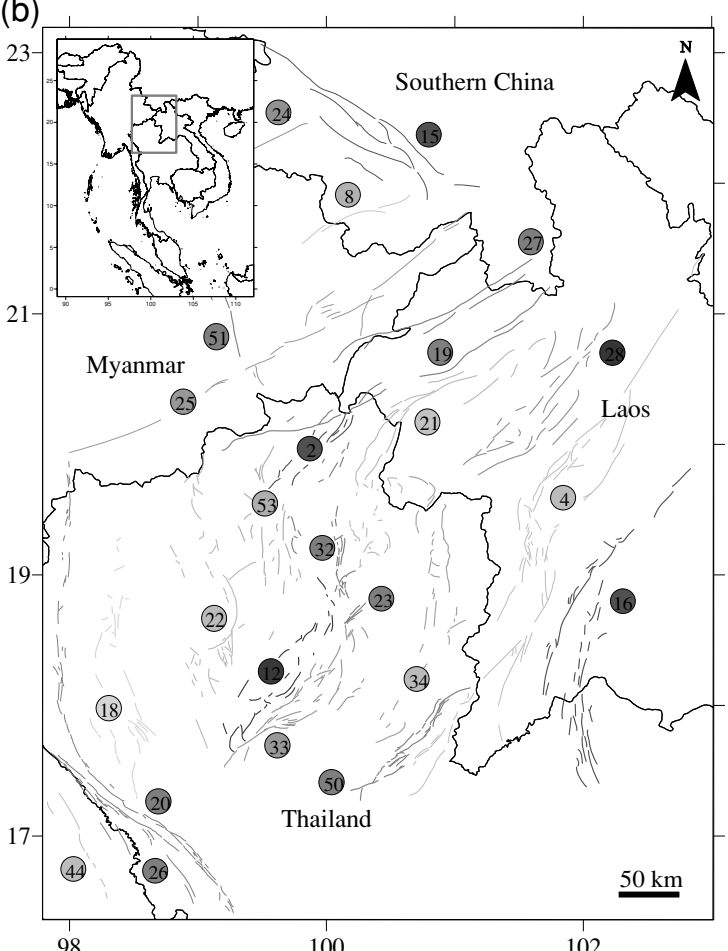

Fig. 1. (a) Active faults in Thailand and adjacent areas interpreted from remote sensing data (IKONOS, LANDSAT, and MODIS) and previous study; (b) enlarged map showing active faults interpreted in northern Thailand and surrounding areas. In both maps, individual fault zones are distinguished by color and numbered. The fault zones can be identified by numbers provided in Table 1 .

ing the regional seismic hazard. Two kinds of seismic hazard analysis were investigated in this study: deterministic seismic hazard analysis (DSHA) (Costa et al., 1992, 1993) and probabilistic seismic hazard analysis (PSHA) (Cornell, 1968). We also used two frequency-magnitude models to evaluate earthquake source potential in our PSHA.

The main objectives of this study were to reveal a worst case scenario for critical seismic hazards in the study area using the DSHA approach and to investigate the sensitivity of PSHA for a non-critical construction plan. We suggest that these complementary DSHA and PSHA approaches can provide a seismic hazard assessment that is more detailed and up-to-date than that currently available. We also expect that engineers will be able to use our results to facilitate the incorporation of seismic design maps into the International Building Code, with the ultimate aim being improved building design and construction.

\section{Seismic Hazard Analysis}

DSHA requires the determination of the expected maximum magnitude or maximum credible earthquake that may occur on individual faults. An empirical strong groundmotion attenuation model is employed to evaluate groundshaking at given sites. The shortest source-to-site distance is then selected and the worst case scenarios for specific areas determined.

In contrast, the PSHA approach estimates the probability that a particular ground-shaking intensity measure $A$ is equal to or exceeds the ground-shaking level $A_{0}$ (Cornell,
1968):

$$
\begin{aligned}
\lambda\left(A \geq A_{0}\right)= & \sum_{i=1}^{N_{\mathrm{s}}} v_{i} \iint P\left[A(m, r) \geq A_{0} \mid m, r\right] \\
& \cdot f_{M_{i}}(m) f_{R_{i}}(r) d m d r,
\end{aligned}
$$

where $\lambda\left(A \geq A_{0}\right)$ represents the frequency of exceedance of a given threshold value $A_{0} ; f_{M_{i}}(m)$ is the probability density function that describes the probability of occurrence of each earthquake having a magnitude in a given range; $f_{R_{i}}(r)$ is the probability density function for source-to-site distance; $P\left[A(m, r) \geq A_{0} \mid m, r\right]$ is the probability of exceedance of a threshold value $A_{0}$, under the condition that an event of magnitude $m$ occurred at source-to-site distance $r$. The value of $P\left[A(m, r) \geq A_{0} \mid m, r\right]$ depends on the strong ground-motion attenuation model used. The coefficient $v_{i}$ represents the activity rate, which implies the average rate of earthquake occurrence, for individual fault $i$ from the total of considering fault $\left(N_{\mathrm{s}}\right)$.

When a single fault $i$ is considered to be a threat for the areas of interest, it is critical to select the appropriate frequency-magnitude model (i.e., probability density function) and activity rate. In this study, as mentioned above, we selected two frequency-magnitude models: the exponential magnitude distribution model and the characteristic earthquake model (Youngs and Coppersmith, 1985). 


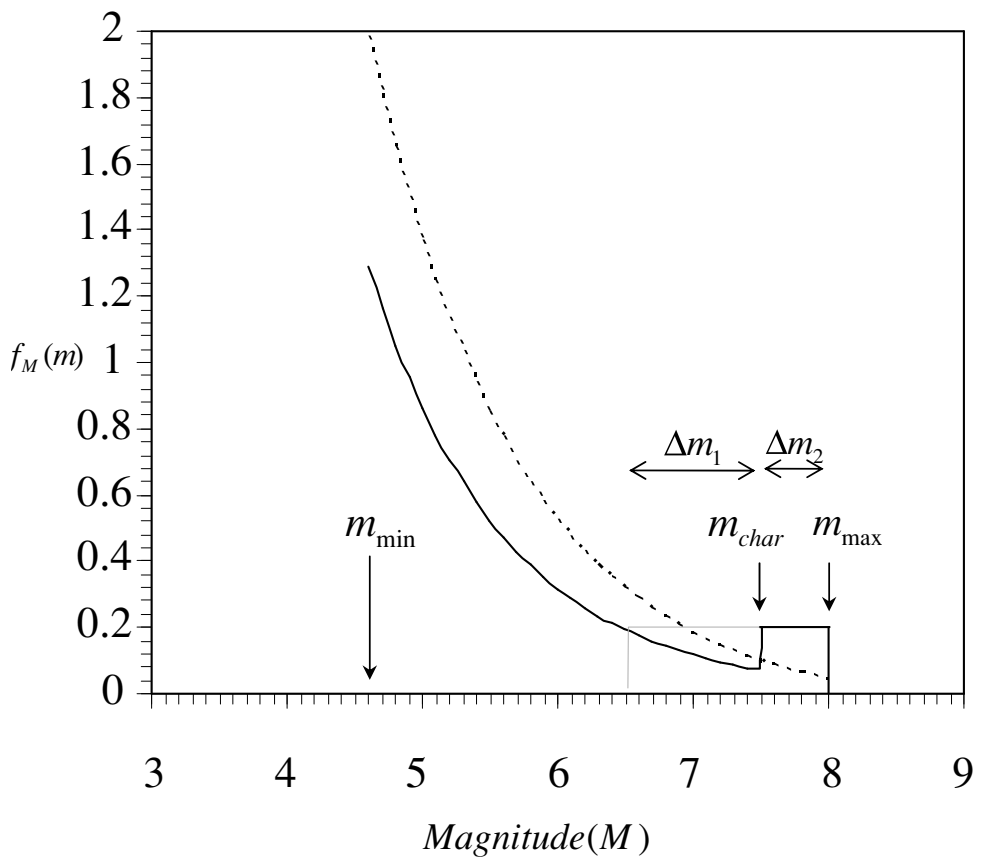

Characteristic

Exponential

Fig. 2. Magnitude probability density function for the exponential magnitude distribution model (dashed line) and for the characteristic earthquake model (solid line) (Convertito et al., 2006).

\subsection{Model 1: Exponential magnitude distribution model}

In general, the probabilities of earthquake occurrence on a given fault follow the Gutenberg-Richter (G-R) relationship (Gutenberg and Richter, 1954; Richter, 1958):

$$
N(m)=10^{a-b m}=e^{(\alpha-\beta m)},
$$

where $N(m)$ is the number of events that are equal to or larger than a given magnitude $m, a$ and $b$ are constants, and $\beta=2.303 b$ and $\alpha=2.303 a$.

Youngs and Coppersmith (1985) proposed the exponential magnitude distribution approach to deal with maximum magnitude $\left(m_{\max }\right)$ and minimum magnitude $\left(m_{\min }\right)$ on individual earthquake sources. The lower threshold $m_{\min }$ can be evaluated from earthquake catalog data. If $m_{\max }$ is known or can be estimated, the cumulative distribution function for the G-R relationship, with upper and lower bounds, can be expressed as an exponential magnitude distribution model $\left(f_{M \exp }(m)\right)$ as follows (dashed line in Fig. 2):

$$
f_{M \exp }(m)= \begin{cases}0 & \text { for } m<m_{\min }, \\ \frac{\beta e^{-\beta\left(m-m_{\min }\right)}}{1-e^{-\beta\left(m_{\max }-m_{\min }\right)}} & \text { for } m_{\min } \leq m \leq m_{\max } \\ 0 & \text { for } m>m_{\max }\end{cases}
$$

Youngs and Coppersmith (1985) also determined an expression for the activity rate $\left(v_{\exp }\right)$ for the exponential magnitude distribution model:

$$
v_{\exp }=\frac{\mu A_{\mathrm{f}} S(c-b)\left[1-e^{-\beta\left(m_{\max }-m_{\min }\right)}\right]}{b M_{0}^{\max } e^{-\beta\left(m_{\max }-m_{\min }\right)}},
$$

where $\mu$ is the rigidity or shear modulus (usually taken to be $\sim 3 \times 10^{2}$ newtons $\left./ \mathrm{m}^{2}\right), A_{\mathrm{f}}$ is the rupture area $\left(\mathrm{km}^{2}\right), S$ is the slip rate (mm/year) for individual faults, $M_{0}^{\max }$ is the seismic moment for $m_{\max }$, and $c$ is a constant derived from the relationship between seismic moment $\left(M_{0}\right)$ and magnitude ( $m$ ) (Eq. (5)). The relationship between $M_{0}$ and $m$ has not previously been proposed for the Thailand region. In this study, therefore, we assume that the constants $c=1.5$ and $d=16.1$, as proposed by Hanks and Kanamori (1979):

$$
\log M_{0}=c m+d
$$

\subsection{Model 2: Characteristic earthquake model}

This model is based on the hypothesis that individual faults tend to generate similar-sized or "characteristic" earthquakes and that these characteristic earthquakes occur on a fault not to the exclusion of all other magnitudes, but with a non-exponential frequency distribution (solid line in Fig. 2) (Youngs and Coppersmith, 1985; Convertito et al., 2006). When the characteristic earthquake model is assumed, it is possible to formulate the corresponding $\left(f_{M \text { char }}(m)\right)$ as follows:

$$
f_{M \text { char }}(m)=\left\{\begin{array}{l}
0 \\
\quad \text { for } m<m_{\min }, \\
\frac{\beta e^{-\beta\left(m-m_{\min }\right)}}{1-e^{-\beta\left(m_{\max }-m_{\min }\right)}} \frac{1}{1+c} \\
\text { for } m_{\min } \leq m \leq m_{\mathrm{char}}=m_{\max }-\Delta m_{2}, \\
\frac{\beta e^{-\beta\left(m_{\max }-m_{\min }-\Delta m_{1}-\Delta m_{2}\right)}}{1-e^{-\beta\left(m_{\max }-m_{\min }-\Delta m_{2}\right)}} \frac{1}{1+c} \\
\text { for } m_{\max }-\Delta m_{2}=m_{\text {char }} \leq m \leq m_{\max }, \\
0 \quad \text { for } m>m_{\max } .
\end{array}\right.
$$


Here, the constant $c$ in Eq. (6) is given by:

$$
c=\frac{\beta e^{-\beta\left(m_{\max }-m_{\min }-\Delta m_{1}-\Delta m_{2}\right)}}{1-e^{-\beta\left(m_{\max }-m_{\min }-\Delta m_{2}\right)}} \Delta m_{2}
$$

Parameters $\beta, m, m_{\min }$, and $m_{\max }$ are the same as in previous equations; $\Delta m_{1}$ and $\Delta m_{2}$ represent two intervals, below and above the magnitude level $m_{\text {char }}$, respectively, which is the characteristic earthquake magnitude (Fig. 2). Youngs and Coppersmith (1985) proposed values of 1.0 for $\Delta m_{1}$ and 0.5 for $\Delta m_{2}$. Note the unique characteristic of $f_{M \text { char }}(m)$, which refers to earthquakes with a magnitude in the range from $m_{\text {char }}$ to $m_{\max }$ (the "black plateau" part of the curve of Fig. 2). Youngs and Coppersmith (1985) also showed that the activity rate $\left(v_{\text {char }}\right)$ between $m_{\text {char }}$ and $m_{\text {max }}$ is given by:

$$
v_{\text {char }}=v_{\mathrm{NC}} \frac{\beta \Delta m_{2} e^{-\beta\left(m_{\max }-m_{\min }-\Delta m_{1}-\Delta m_{2}\right)}}{1-e^{-\beta\left(m_{\max }-m_{\min }-\Delta m_{2}\right)}},
$$

where $v_{\mathrm{NC}}($ Eq. $(8))$ represents the activity rate for the noncharacteristic part $\left(m_{\min } \leq m \leq m_{\text {char }}\right)$ of $f_{M \text { char }}(m)$ :

$$
v_{\mathrm{NC}}=\frac{\mu A_{\mathrm{f}} S\left[1-e^{-\beta\left(m_{\max }-m_{\min }-\Delta m_{2}\right)}\right]}{K M_{0}^{\max } e^{-\beta\left(m_{\max }-m_{\min }-\Delta m_{2}\right)}} .
$$

The constant $K$ is given by

$$
K=\frac{b 10^{-c \Delta m_{2}}}{c-b} \frac{b e^{\beta \Delta m_{1}}\left(1-10^{-c \Delta m_{2}}\right)}{c} .
$$

In summary, for PSHA, using either the exponential magnitude distribution model or the characteristic earthquake model, the data necessary to evaluate earthquake source potential are the maximum magnitude $\left(m_{\max }\right)$, minimum magnitude $\left(m_{\min }\right)$, slip rate $(S)$, earthquake rupture area $\left(A_{\mathrm{f}}\right)$, and $a$ and $b$ values from the G-R relationship.

\section{Materials and Methods}

\subsection{Active fault data}

The basic material underpinning the seismic hazard analysis of this study was an active fault map of the study area. We identified active faults in Thailand and neighboring areas from high-resolution remote sensing data. We also analyzed satellite images from IKONOS, LANDSAT, and MODIS, including a digital elevation model with 90-m resolution. The names and locations of individual fault zones are cited mostly from previous publications, but there are also new fault zones proposed in this study (Fig. 1; Table 1).

3.1.1 Active faults outside Thailand Identified active faults outside Thailand are distributed mainly in central Myanmar, on Sumatra Island, in the Laos-southern China border region, and in northern Vietnam (Fig. 1(a)). The major active fault zone in Myanmar is the strike-slip Sagiang fault zone (Bertrand and Rangin, 2003) (no. 38 in Fig. 1(a)). This fault zone traverses the central part of Myanmar from north to south. Although a morphotectonic representation of this feature cannot be identified in the Andaman Sea, present-day earthquake records show that the Sagiang fault extends southward into the Andaman Sea and joins with the clearly defined fault zones of inland Sumatra (Petersen et al., 2004). We therefore defined the Sumatra fault zone as the southern extension of the Sagiang fault (no. 38 in Fig. 1(a)). In the Laos-southern China border region, there are a large number of fault and shear zones caused by the collision of the Indian and Eurasian tectonic plates (Polachan et al., 1991). These include the Chong Shan shear zone (Akciz et al., 2008), the Dein Bein Fu fault zone (Zuchiewicz et al., 2004), the Gaoligong Shan shear zone (Akciz et al., 2008), the Hsenwi-Nanting fault zone (Lacassin et al., 1998), and the Linchang fault zone (Lacassin et al., 1998) (nos. 3, 4, 6, 7, and 15 in Fig. 1(a) and Table 1). Present-day earthquake records show that these complex zones have generated seismic activity continuously since the start of record keeping. In northern Vietnam, the longest fault zone is the Red River fault zone (Duong and Feigl, 1999) (no. 37 in Fig. 1(a)). A number of other obvious fault zones have been reported in this region, such as the Cao Bang-Tien Yen (Cuong et al., 2006), Dong Trieu (Charusiri et al., 2002), Song Ca (Takemoto et al., 2005), Song Chay (Cuong and Zuchiewicz, 2001), and Song Da and Song Ma (Phoung, 1991) fault zones (nos. 1, 5, 40, 41, 42, and 43 in Fig. 1(a) and Table 1). All of these fault zones have a NW-SE orientation. Present-day earthquake records from this area show that earthquakes are commonly associated with these fault zones.

3.1.2 Active faults in Thailand There are a large number of active fault zones in northern Thailand, including the Lampang-Thoen (Charusiri et al., 2004), Mae Chan (Fenton et al., 2003), Mae Tha (Rhodes et al., 2004), and Phrae (Fenton et al., 2003) fault zones (nos. 12, 19, 22, and 33 in Fig. 1(b) and Table 1). These fault zones are associated with Cenozoic intermontane grabens and half grabens between intra-plate basins in northern Thailand and consist of north- to northwest-striking normal to transextensional faults and northeast-striking left-lateral strikeslip faults (Fenton et al., 2003).

There are four major fault zones in western Thailand: the Mae Hong Sorn-Tak (Charusiri et al., 2004), Sri Sawat (Songmuang et al., 2007), Three Pagoda (Fenton et al., 2003) fault zones, and the newly defined Moei-Tongyi fault zone (no. 20 in Fig. 1(b) and nos. 44, 49, and 26 in Fig. 1(a) and Table 1). We grouped the Moei-Mae Ping fault (Saithong et al., 2005) and the Tongyi fault (Nutalaya et al., 1985) into the Moei-Tongyi fault zone on the basis of morphotectonic evidence from satellite imagery.

The Ongkalak fault zone (no. 29 in Fig. 1(a)) was identified in central Thailand by Charusiri (2005), who considered it to be a branch of the Moei-Tongyi fault. However, it was previously named the Mae Ping fault by Polachan et al. (1991). Although there is no evidence of presentday seismicity in the Ongkalak fault zone, a paleoseismological study by Charusiri (2005) indicated a slip rate of $0.17 \mathrm{~mm} / \mathrm{yr}$ and suggested that the fault zone is capable of generating an earthquake up to $M_{\mathrm{w}} 7$. We consider the Ongkalak fault zone to be one of the major earthquake sources in central Thailand.

Tthere are two major active faults in southern Thailand: the Klong Marui fault zone in the north and the Ranong fault zone in the south (Wong et al., 2005) (nos. 10 and 36 in Fig. 1(a) and Table 1). Both fault zones strike NE-SW.

The northeastern highlands of Thailand are far from 
Table 1. Summary of the earthquake potential parameters of the active fault zones used for seismic hazard analysis in Thailand and adjacent areas.

\begin{tabular}{|c|c|c|c|c|c|c|c|c|c|c|}
\hline \multirow[t]{2}{*}{ Fault no. } & \multirow[t]{2}{*}{ Fault zone } & \multicolumn{5}{|c|}{ Active fault data } & \multicolumn{3}{|c|}{ Seismicity investigation } & \multirow[t]{2}{*}{ Source } \\
\hline & & Fault type $^{\mathrm{a}}$ & $\begin{array}{l}\text { SRL } \\
(\mathrm{km})\end{array}$ & $\begin{array}{c}S \\
(\mathrm{~mm} / \mathrm{yr})\end{array}$ & $m_{\max }$ & $\begin{array}{c}A_{\mathrm{f}} \\
\left(\mathrm{km}^{2}\right)\end{array}$ & $m_{\min }$ & $a$ value & $b$ value & \\
\hline 1 & Cao Bang-Tien Yen & $\mathrm{S}$ & 287 & - & 7.9 & 5,000 & 4.0 & 1.50 & 0.34 & Cuong et al. (2006) \\
\hline 2 & Chiang Rai & $\mathrm{S}$ & 28 & - & 6.8 & 499 & 4.0 & 2.25 & 0.42 & This study \\
\hline 3 & Chong Shan shear zone & $\mathrm{S}$ & 298 & 5.00 & 8.0 & 6,166 & 4.0 & 7.85 & 1.34 & Akciz et al. (2008) \\
\hline 4 & Dein Bein $\mathrm{Fu}$ & $\mathrm{S}$ & 130 & 2.00 & 7.5 & 2,163 & 4.0 & 2.68 & 0.37 & Zuchiewicz et al. (2004) \\
\hline 5 & Dong Trieu & $\mathrm{S}, \mathrm{N}$ & 187 & - & 7.7 & 3,289 & 4.0 & 2.71 & 0.90 & Charusiri et al. (2002) \\
\hline 6 & Gaoligong Shan shear zone & $\mathrm{S}$ & 407 & 5.00 & 8.1 & 7,603 & 4.0 & 9.67 & 1.62 & Akciz et al. (2008) \\
\hline 7 & Hsenwi-Nanting & $\mathrm{S}$ & 359 & 1.00 & 8.0 & 6,166 & 4.0 & 25.80 & 4.83 & Lacassin et al. (1998) \\
\hline 8 & Jinghong & $\mathrm{S}$ & 53 & - & 7.1 & 935 & 4.0 & 2.33 & 0.40 & Lacassin et al. (1998) \\
\hline 9 & Kawthuang & - & 36 & - & 6.9 & 615 & 4.0 & 1.68 & 0.25 & This study \\
\hline 10 & Klong Marui & $\mathrm{S}$ & 29 & 0.10 & 6.8 & 499 & 4.0 & 1.68 & 0.25 & Wong et al. (2005) \\
\hline 11 & Kungyaungale & $\mathrm{S}$ & 25 & 4.00 & 6.7 & 405 & 4.0 & 1.68 & 0.25 & Wong et al. (2005) \\
\hline 12 & Lampang-Thoen & $\mathrm{S}, \mathrm{N}$ & 28 & 0.83 & 6.8 & 499 & 4.0 & 2.72 & 0.55 & Charusiri et al. (2004) \\
\hline 13 & Lashio & $\mathrm{S}$ & 50 & 1.00 & 7.0 & 759 & 4.0 & 3.15 & 0.40 & Lacassin et al. (1998) \\
\hline 14 & Libir & - & 170 & - & 7.7 & 3,289 & 4.0 & 3.44 & 0.60 & Metcalfe (2000) \\
\hline 15 & Linchang & $\mathrm{S}$ & 107 & - & 7.4 & 1,754 & 4.0 & 2.33 & 0.29 & Lacassin et al. (1998) \\
\hline 16 & Loei-Petchabun Suture & $\mathrm{S}$ & 59 & - & 7.1 & 935 & 4.0 & 3.01 & 0.62 & Lepvrier et al. (2004) \\
\hline 17 & Longling-Ruili & $S$ & 70 & 5.00 & 7.2 & 1,153 & 4.0 & 6.42 & 1.01 & Bai and Meju (2003) \\
\hline 18 & Mae Chaem & - & 21 & - & 6.6 & 328 & 4.0 & 1.89 & 0.32 & This study \\
\hline 19 & Mae Chan & $\mathrm{S}$ & 99 & 3.00 & 7.4 & 1754 & 4.0 & 2.64 & 0.37 & Fenton et al. (2003) \\
\hline 20 & Mae Hong Sorn-Tak & $\mathrm{S}$ & 37 & - & 6.9 & 615 & 4.0 & 2.65 & 0.38 & Charusiri et al. (2004) \\
\hline 21 & Mae Ing & $\mathrm{S}$ & 38 & - & 6.9 & 615 & 4.0 & 2.56 & 0.38 & Fenton et al. (2003) \\
\hline 22 & Mae Tha & $\mathrm{S}$ & 47 & 0.80 & 7.0 & 759 & 4.0 & 2.36 & 0.38 & Rhodes et al. (2004) \\
\hline 23 & Mae Yom & $\mathrm{S}$ & 22 & 0.80 & 6.6 & 328 & 4.0 & 1.92 & 0.60 & RID (2006) \\
\hline 24 & Menglian & $\mathrm{S}$ & 117 & 0.50 & 7.5 & 2,163 & 4.0 & 2.13 & 0.28 & Lacassin et al. (1998) \\
\hline 25 & Mengxing & $\mathrm{S}$ & 75 & 4.80 & 7.3 & 1,422 & 4.0 & 2.95 & 0.40 & Lacassin et al. (1998) \\
\hline 26 & Moei-Tongyi & $S$ & 259 & 0.73 & 7.9 & 5,000 & 4.0 & 3.46 & 0.54 & This study \\
\hline 27 & Nam Ma & $\mathrm{S}$ & 177 & 2.40 & 7.7 & 3,289 & 4.0 & 3.18 & 0.58 & Morley (2007) \\
\hline 28 & Nam Peng & $\mathrm{S}$ & 51 & - & 7.1 & 935 & 4.0 & 3.08 & 0.59 & Charusiri et al. (1999) \\
\hline 29 & Ongkalak & $\mathrm{S}, \mathrm{N}$ & 47 & 0.17 & 7.0 & 759 & 4.0 & 2.52 & 0.40 & Charusiri (2005) \\
\hline 30 & Pa Pun & $\mathrm{S}$ & 143 & - & 7.6 & 2,667 & 4.0 & 2.58 & 0.37 & Nutalaya et al. (1985) \\
\hline 31 & Pan Luang & $\mathrm{S}$ & 219 & - & 7.8 & 4,055 & 4.0 & 2.98 & 0.51 & Nutalaya et al. (1985) \\
\hline 32 & Pha Yao & $\mathrm{S}, \mathrm{N}$ & 20 & 0.10 & 6.6 & 328 & 4.0 & 2.95 & 0.40 & Fenton et al. (2003) \\
\hline 33 & Phrae & $\mathrm{S}$ & 28 & 0.10 & 6.8 & 499 & 4.0 & 2.68 & 0.53 & Fenton et al. (2003) \\
\hline 34 & Pua & $\mathrm{N}$ & 29 & 0.60 & 6.8 & 499 & 4.0 & 2.44 & 0.55 & Fenton et al. (2003) \\
\hline 35 & Qiaohou & - & 145 & - & 7.6 & 2,667 & 4.0 & 2.35 & 0.25 & Lacassin et al. (1998) \\
\hline 36 & Ranong & $\mathrm{S}$ & 46 & 1.00 & 7.0 & 759 & 4.0 & 1.68 & 0.25 & Wong et al. (2005) \\
\hline 37 & Red River & $\mathrm{S}$ & 812 & 4.00 & 8.5 & 17,579 & 4.0 & 17.60 & 3.16 & Duong and Feigl (1999) \\
\hline 38 & Sagiang-Sumatra & $\mathrm{S}$ & 958 & 23.00 & 8.5 & 17,579 & 4.0 & 6.92 & 0.86 & Bertrand and Rangin (2003) \\
\hline 39 & Shan & $\mathrm{S}$ & 66 & - & 7.2 & 1,153 & 4.0 & 2.93 & 0.39 & This study \\
\hline 40 & Song $\mathrm{Ca}$ & $\mathrm{S}$ & 225 & - & 7.8 & 4,055 & 4.0 & 2.58 & 0.48 & Takemoto et al. (2005) \\
\hline 41 & Song Chay & $\mathrm{S}, \mathrm{N}$ & 55 & 2.00 & 7.1 & 935 & 4.0 & 3.05 & 0.58 & Cuong and Zuchiewicz (2001) \\
\hline 42 & Song Da & $\mathrm{S}$ & 46 & - & 7.0 & 759 & 4.0 & 2.73 & 0.45 & Phoung (1991) \\
\hline 43 & Song Ma & $\mathrm{S}$ & 72 & - & 7.2 & 1,153 & 4.0 & 6.52 & 1.06 & Phoung (1991) \\
\hline 44 & Sri Sawat & $\mathrm{S}$ & 43 & 2.00 & 7.0 & 759 & 4.0 & 2.50 & 0.40 & Songmuang et al. (2007) \\
\hline 45 & Andaman subduction & $\mathrm{R}$ & 3,388 & 47.00 & 9.2 & 76,208 & 4.0 & 6.08 & 0.69 & Paul et al. (2001) \\
\hline 46 & Tavoy & $\mathrm{S}$ & 32 & - & 6.8 & 499 & 4.0 & 2.80 & 0.79 & Wong et al. (2005) \\
\hline 47 & Tenasserim & $\mathrm{S}$ & 50 & 4.00 & 7.0 & 759 & 4.0 & 1.68 & 0.25 & Wong et al. (2005) \\
\hline 48 & Tha Khaek & $\mathrm{S}$ & 250 & - & 7.9 & 5,000 & 4.0 & 3.15 & 0.67 & DMR (2006) \\
\hline 49 & Three Pagoda & $\mathrm{S}$ & 141 & 2.00 & 7.6 & 2,667 & 4.0 & 2.62 & 0.51 & Fenton et al. (2003) \\
\hline 50 & Uttaladith & $\mathrm{S}$ & 27 & 0.10 & 6.7 & 405 & 4.0 & 1.63 & 0.46 & Fenton et al. (2003) \\
\hline 51 & Wan Na-awn & - & 69 & - & 7.2 & 1,153 & 4.0 & 2.28 & 0.35 & This study \\
\hline 52 & Wanding & $\mathrm{S}$ & 199 & 1.90 & 7.7 & 3,289 & 4.0 & 5.34 & 0.93 & Morley (2007) \\
\hline 53 & Wang Nua & - & 31 & - & 6.8 & 499 & 4.0 & 2.27 & 0.40 & This study \\
\hline 54 & Xianshuihe & $\mathrm{S}$ & 505 & 15.00 & 8.2 & 9,376 & 4.0 & 6.74 & 1.05 & Eleftheria et al. (2004) \\
\hline 55 & Hutgyi & $\mathrm{S}, \mathrm{R}$ & 5 & 0.03 & 5.9 & 76 & 4.0 & 1.67 & 0.34 & EGAT (2006) \\
\hline
\end{tabular}

SRL is surface rupture length $(\mathrm{km}), m_{\max }$ is maximum possible earthquake magnitude calculated from empirical relationship between SRL and $M_{\mathrm{W}}$ (Wells and Coppersmith, 1994), $A_{\mathrm{f}}$ is rupture area $\left(\mathrm{km}^{2}\right)$ calculated from the empirical relationship between and $A_{\mathrm{f}}$ (Wells and Coppersmith, 1994), $S$ is slip rate $(\mathrm{mm} / \mathrm{yr}), m_{\min }$ is the minimum magnitude. ${ }^{a}$ Fault type: $\mathrm{S}=$ strike-slip fault, $\mathrm{N}=$ normal fault, $\mathrm{R}=$ reverse fault. 
known earthquake sources. The closest candidate is the Tha Khaek fault zone (DMR, 2006) (no. 48 in Fig. 1(a)) near the Thailand-Laos border. This fault zone is clearly indicated by the satellite image investigations, and one earthquake was recorded in 1988 and in 1997 with a local magnitude $\left(M_{\mathrm{L}}\right)$ of 4.1 and 4.2 , respectively. We therefore regard this fault zone to be one of the earthquake sources to be considered in this study.

3.1.3 Maximum magnitudes and slip rates After identifying 55 candidate active fault zones, we evaluated the earthquake potential of each zone by using both active fault data and seismicity data. To determine the possible $m_{\max }$, we used the relationship between $M_{\mathrm{w}}$ and fault rupture length at the surface (SRL), as proposed by Wells and Coppersmith (1994) (Eq. (10)). The SRL used for the $M_{\mathrm{w}}$ calculation is taken from the length of the longest fault segment in each fault zone. We then determined the rupture area $A_{\mathrm{f}}$ by using the empirical relationship between the obtained $M_{\mathrm{w}}$ from Eq. (10) and $A_{\mathrm{f}}$ (Wells and Coppersmith, 1994) of Eq. (11):

$$
\begin{aligned}
M_{\mathrm{w}} & =5.08+1.16 \log (\mathrm{SRL}), \\
\log \left(A_{\mathrm{f}}\right) & =-3.49+0.91 M_{\mathrm{w}},
\end{aligned}
$$

where $M_{\mathrm{w}}$ is moment magnitude, SRL is surface rupture length of the fault $(\mathrm{km})$, and $A_{\mathrm{f}}$ is the rupture area of the fault $\left(\mathrm{km}^{2}\right)$.

For many of the faults within the study area, there have been few studies of slip rate $(S)$. However, we conducted a comprehensive literature search for information about slip rates, which are summarized in Table 1.

\subsection{Earthquake catalog data}

Although earthquake catalogs cover a much shorter time period than paleoseismological data, the earthquake records they provide are indispensable for seismic hazard analyses. In this study, we obtained several parameters necessary to determine earthquake potential from earthquake catalog records. The methodology we used to evaluate the seismicity data (earthquake catalogs) in each fault zone is based on the method proposed by Caceres and Kulhanek (2000) as follows:

- First, we collected earthquake records from various earthquake catalogs, such as the Incorporated Research Institutions for Seismology (IRIS), the global CMT catalogue, and the Thai Meteorological Department. We then constructed a composite earthquake catalog and eliminated overlapping earthquake events.

- We converted the various earthquake magnitude scales (i.e., body-wave magnitude $\left(m_{\mathrm{b}}\right)$, surface-wave magnitude $\left(M_{\mathrm{s}}\right)$, local magnitude $\left(M_{\mathrm{L}}\right)$, and $\left.M_{\mathrm{w}}\right)$ in the composite earthquake catalog to moment magnitude $\left(M_{\mathrm{w}}\right)$, which represents the physical properties of the earthquake source and avoids the "saturation phenomenon" at large seismic moments (e.g., Howell, 1981; Ottemoller and Havskov, 2003). The global CMT catalogue provides $m_{\mathrm{b}}, M_{\mathrm{s}}$, and $M_{\mathrm{w}}$ magnitudes for individual earthquake events; we used these data from our study area to calibrate the relationship of $M_{\mathrm{w}}$ to both $m_{\mathrm{b}}$ and $M_{\mathrm{s}}$. The relationships of $M_{\mathrm{w}}$ to $m_{\mathrm{b}}$ and $M_{\mathrm{S}}$ are formulated in Eqs. (12) and (13). For $M_{\mathrm{L}}$, we used the empirical relationship between $M_{\mathrm{L}}$ and $m_{\mathrm{b}}$ of Palasri (2006) (Eq. (14)) and then converted $m_{\mathrm{b}}$ to $M_{\mathrm{w}}$ using our Eq. (12).

$$
\begin{array}{rlr}
M_{\mathrm{w}}=0.0167 m_{\mathrm{b}}^{2}+0.8438 m_{\mathrm{b}}+0.9071 ; & m_{\mathrm{b}} \leq 6.8 \\
M_{\mathrm{w}}=0.028 M_{\mathrm{s}}^{2}+0.3364 M_{\mathrm{s}}+3.2574 ; & M_{\mathrm{s}} \leq 7.6 \\
m_{\mathrm{b}}=1.64+0.63 M_{\mathrm{L}} ; & M_{\mathrm{L}} \leq 6.8
\end{array}
$$

- For conventional seismic hazard analysis, independent earthquake (main shock) events must be considered (Cornell, 1968). To satisfy this requirement, earthquakes in the study area were de-clustered to remove foreshocks and aftershocks by using the method of Gardner and Knopoff (1974).

- Thereafter, for each fault zone, the independent earthquakes within a $60-\mathrm{km}$-wide corridor straddling the fault zone were identified as representatives of the earthquake activity in that fault zone. The cumulative numbers of earthquakes within individual fault zones were plotted against moment magnitude to obtain G$\mathrm{R}$ relationships. For this, we used ZMAP software (Wiemer, 2001) to estimate the optimal $a$ and $b$ values that best yielded the relationship between observed $N(m)$ and $m$ (Eq. (2)) for each fault zone. For all fault zones in this study, the $m_{\min }$ is taken as 4.0. Below this lower threshold magnitude (i.e., $m_{\min }$ ), it is assumed that there is not any significant earthquake hazard on engineering structures (Kramer, 1996).

All fundamental earthquake source parameters (i.e., $m_{\max }, m_{\min }, A_{\mathrm{f}}, S$, and $a$ and $b$ values) of the 55 earthquake sources are summarized in Table 1.

\section{Strong Ground-Motion Attenuation Models}

When earthquake potential parameters for individual fault zones have been determined, the next step for seismic hazard analysis is to select an appropriate strong groundmotion attenuation model. The characteristics of strong ground-motion attenuation are area-dependent and influenced by the local tectonic setting (e.g., subduction zone or inland continental region). We separated the 55 active fault zones into two seismotectonic provinces on the basis of tectonic setting: the subduction zone earthquake province for the Andaman subduction zone, and the shallow crustal earthquake province for the other 54 fault zones.

For the Andaman subduction zone, Petersen et al. (2004) compared previously used strong ground-motion attenuation models with the strong ground-motion data recorded by the IRIS network and suggested that the Andaman subduction zone shows the attenuation behavior of ground shaking consistent with that of Youngs et al. (1997) (Eq. (15)), but only if the source-to-site distance $(R)$ is less than $200 \mathrm{~km}$.

$$
\begin{aligned}
\ln y_{\text {Youngs }}(M, R)= & C_{1}^{*}+C_{2} M+C_{3}^{*} \ln \left[R+e^{C_{4}^{*}-\frac{C_{2}}{C_{3}} M}\right] \\
& +C_{5} Z_{S S}+C_{8} Z_{t}+C_{9} H \\
\text { with } C_{1}^{*}= & C_{1}+C_{3} C_{4}-C_{3}^{*} C_{4}^{*} \\
C_{3}^{*}= & C_{3}+C_{6} Z_{S S} \\
C_{4}^{*}= & C_{4}+C_{7} Z_{S S}
\end{aligned}
$$

where $y$ is peak horizontal ground acceleration $\left(\mathrm{cm} / \mathrm{s}^{2}\right)$, 


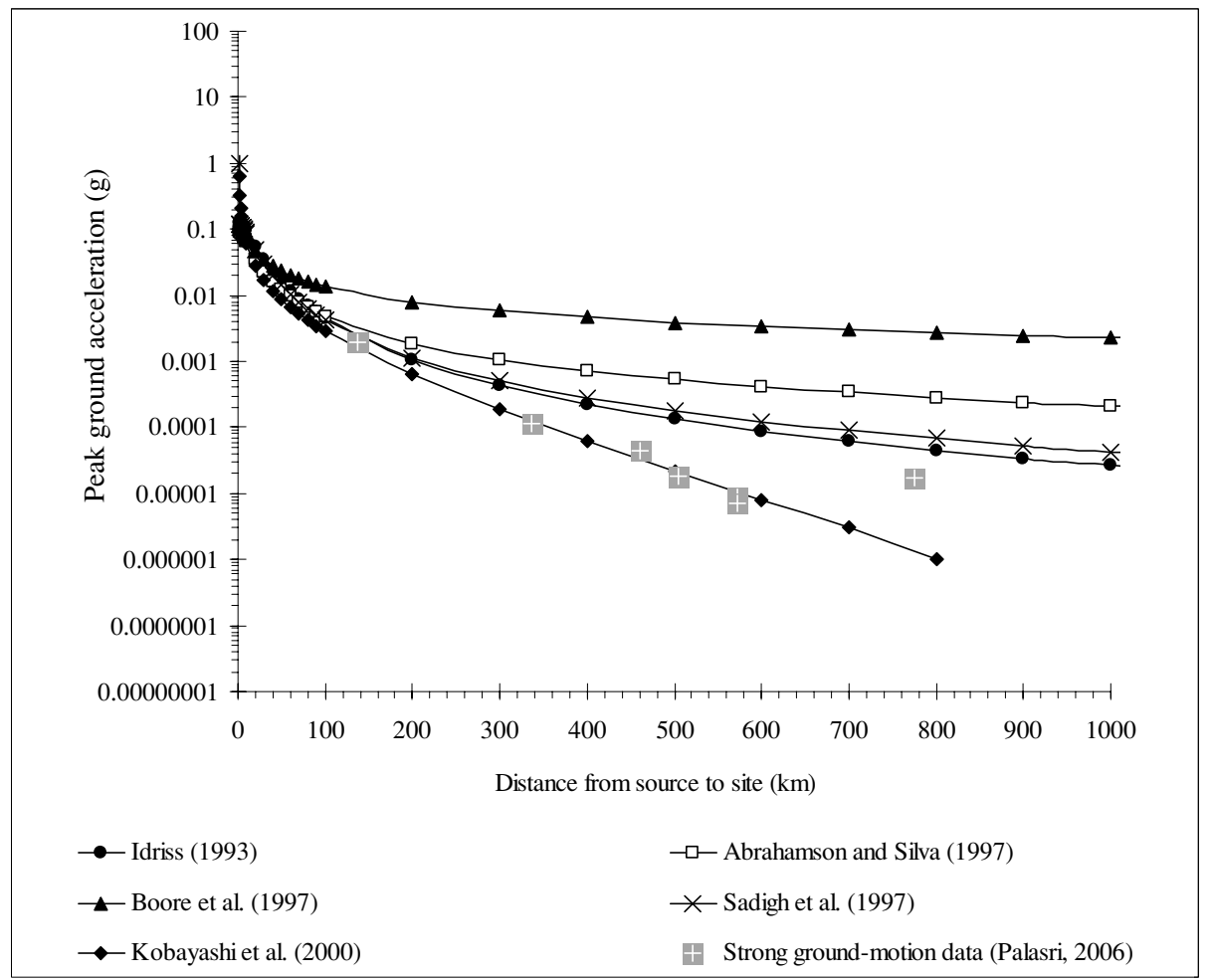

Fig. 3. Comparison of published strong ground-motion attenuation models with strong ground-motion data recorded in Thailand.

$M$ is moment magnitude $\left(M_{\mathrm{w}}\right), R$ is source-to-site distance $(\mathrm{km}), C_{1}=0.2418, C_{2}=1.414, C_{3}=-2.552$, $C_{4}=\ln (1.7818), C_{8}=0.3846$, and $C_{9}=0.00607 . Z_{S S}$ is zero for a rock site and one for a soil site, and $Z_{t}$ is zero for plate-interface earthquakes (low-angle, thrust-faulting earthquakes at plate interfaces), and one for intraslab earthquakes (high-angle, predominantly normal-faulting earthquakes within subducting plates). $H$ is focal depth. The other coefficients in Eq. (15) are not required for a rock site. The standard deviation of $\ln y(\sigma)$ for probability of the exceedance calculation is estimated as follows: $\sigma=$ $1.45-0.1 M$.

If the source-to-site distance is $\geq 200 \mathrm{~km}$, the attenuation behavior of Andaman subduction-zone earthquakes is expressed by the following equation (Eq. (16); Petersen et al., 2004):

$\ln y_{\text {Petersen }}(M, R)=\ln y_{\text {Youngs }}(M, R)+[-0.0038 *(R-200)]$.

For the shallow crustal earthquake fault zones, two strong ground-motion attenuation models have been suggested by previous investigations. Warnitchai and Lisantono (1996) applied the attenuation model of Esteva and Villaverde (1973) to seismic hazard analysis in Thailand. However, Palasri (2006) suggested that the attenuation model of Sadigh et al. (1997) is more suitable for Thailand and adjacent areas after comparing it with strong ground-motion data collected by the Thai Meteorological Department.

We compared several recently proposed attenuation models with observed strong ground-motion data from Thailand that were analyzed by Palasri (2006) (Fig. 3). This comparison suggests that an equation proposed by Kobayashi et al. (2000) for the Japan region (Eq. (17)) is the best fit for

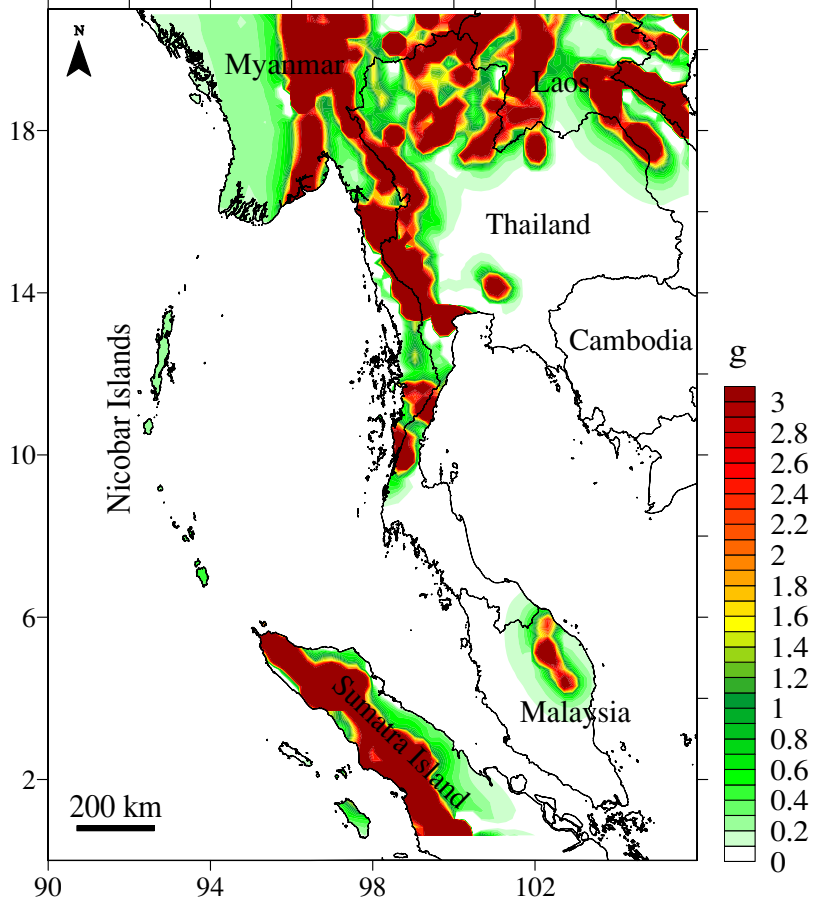

Fig. 4. Deterministic seismic hazard map of Thailand and adjacent areas using active fault data.

these data. We consider Eq. (17) to be suitable to represent the attenuation behavior of shallow crustal earthquakes in the study area.

$\log y(M, R)=a M-b R-\log \left(R+c 10^{d M}\right)+e h+S_{k}$, 


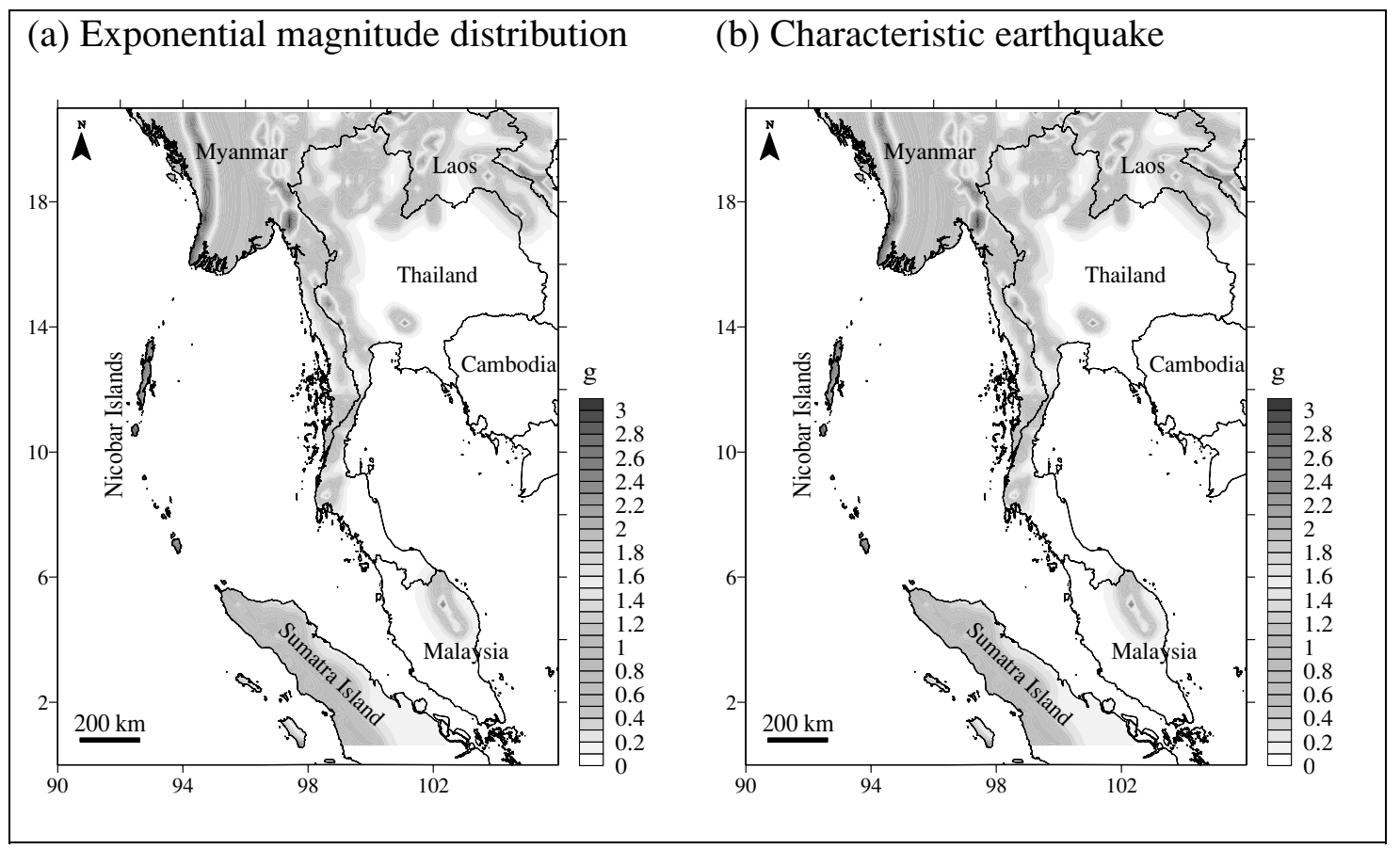

Fig. 5. Probabilistic seismic hazard maps of Thailand and adjacent areas showing $2 \%$ probability of exceedance in 50-year time period. (a) Exponential magnitude distribution model and (b) characteristic earthquake model.

where for any rock site, $y$ is the peak ground acceleration $\left(\mathrm{cm} / \mathrm{s}^{2}\right), M$ is the moment magnitude $\left(M_{\mathrm{w}}\right), R$ is the sourceto-site distance $(\mathrm{km}), a=0.578, b=0.00355, c=$ $0.00661, d=0.00661, e=0.00661, h=10$, and $S_{k}=$ -0.21 . The standard deviation of $\ln y(\sigma)$ for probability of exceedance calculation is 0.213 .

\section{Seismic Hazard Analysis Results \\ 5.1 DSHA}

DSHA (Fig. 4), which does not account for the activity rate of earthquake occurrence, reveals an extremely high hazard level along the active fault zones. The peak ground acceleration (PGA) calculated by DSHA for the maximum credible earthquake ranges from $0 \mathrm{~g}$ in areas far from active faults to $3 \mathrm{~g}$ alongside the active faults. The earthquakeprone areas are in central Myanmar, Sumatra, Laos, southern China, northern Vietnam, and northern and western Thailand. In central Thailand, there is a high hazard level in the area close to the Ongkalak fault zone. There is a seismic hazard associated with the Ranong and Klong Marui fault zones in southern Thailand. For northeastern Thailand, although there has recently been a dramatic decrease in reports of earthquake ground shaking, the calculated seismic hazard reveals that the far north, close to the Tha Khaek Fault in Laos, may be subject to damage by seismic activity. In the Nicobar Islands and western Myanmar, close to the Andaman subduction zone, the DSHA map shows ground shaking of around $0.4-0.6 \mathrm{~g}$.

\subsection{PSHA}

The PSHA initially produced two types of maps using different frequency-magnitude models: the exponential magnitude distribution model and the characteristic earthquake model (Fig. 5). Comparison of the exponential magnitude distribution model and the characteristic earthquake model showed that they both provide similar seismic hazard levels. We attribute this similarity to the similar frequencymagnitude distributions obtained from active fault parameters. We calculated very similar magnitude probability density functions for the two models for two active fault zones and the Andaman subduction zone (Fig. 6). It is difficult to determine which of the two frequency-magnitude models is more appropriate for the study area because no evidence of characteristic earthquakes can be clearly identified in the instrumental earthquake records from 1963 to 2007 (Fig. 7). As a result, we determined the sensitivity of the PSHA results to the weights assigned to the logic-tree branches for both given frequency-magnitude models: the exponential magnitude distribution and characteristic earthquake models. Both of these are weighted in 0.5 probability of occurrence. PSHA maps were produced for bedrock conditions for a $2 \%$ and $10 \%$ probability of exceedance in 10-, 50-, and 100-year time periods (Fig. 8). The spatial distribution of seismic hazard from PSHA is also roughly analogous to that obtained by DSHA, but the maximum hazard level is lower in PSHA than in DSHA.

Taking a $10 \%$ probability of exceedance in a 50 -year time period (Fig. 8(d)), PGA values indicate a high seismic hazard (up to $2 \mathrm{~g}$ ) in countries neighboring Thailand. The trend of PGA in Thailand shows a high hazard level of around $0.8 \mathrm{~g}$ in the north and west, and it decreases gradually toward the east and southeast. One outstandingly high hazard area is in the Ongkalak fault zone in central Thailand, which shows the maximum hazard level in Thailand, up to $2 \mathrm{~g}$. There are two major fault zones in southern Thailand: the Ranong and Klong Marui fault zones. Judging from the surface rupture length of these fault zones, both of them can generate an earthquake with a maximum magnitude of around 6.8-7. However, the Ranong fault zone has a slip 


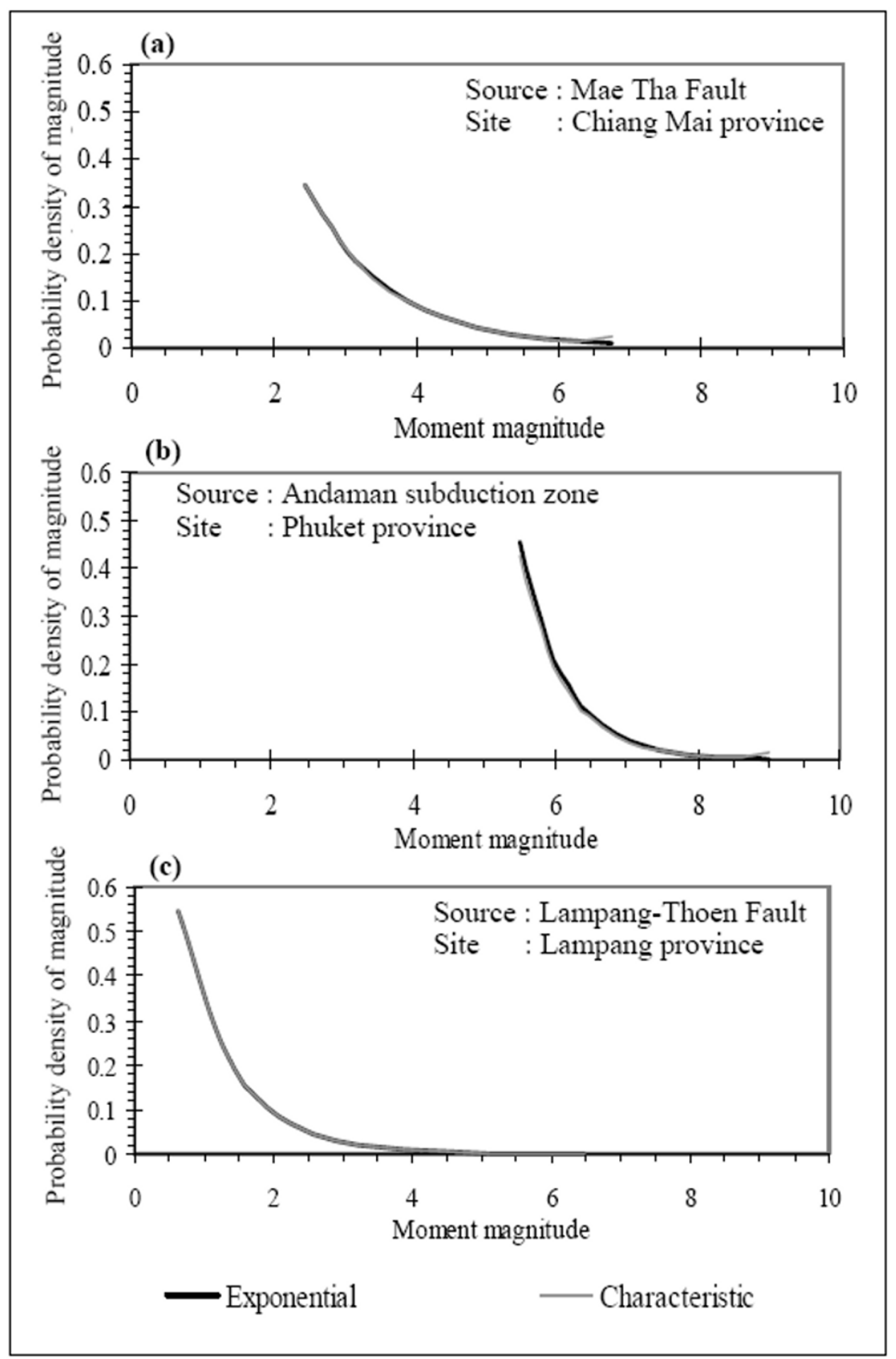

Fig. 6. Comparisons of magnitude probability density functions for (a) the Mae Tha fault, (b) the Andaman subduction zone, and (c) the Lampang-Thoen fault. Gray lines represent the results calculated from the characteristic earthquake model, and black lines represent the exponential magnitude distribution model.

rate of $1 \mathrm{~mm} / \mathrm{yr}$, whereas the slip rate of the Klong Marui fault zone is $0.1 \mathrm{~mm} / \mathrm{yr}$ (Table 1). The Klong Marui fault zone, therefore, does not have any significant effect on seismic hazard in this area.

\section{Discussion and Conclusions}

We have used active fault parameters estimated from remote sensing data and previous studies, including the best- fit strong ground-motion attenuation models, to evaluate the seismic hazard in Thailand and adjacent areas.

For DSHA, we assumed a worst case scenario for each active fault zone. The PGA values from DSHA were up to 2-3 g along many active fault zones; this result may be somewhat overestimated because of the conservatively determined $m_{\max }$ from the limited amount of active fault data. Although most of the earthquakes during this period 


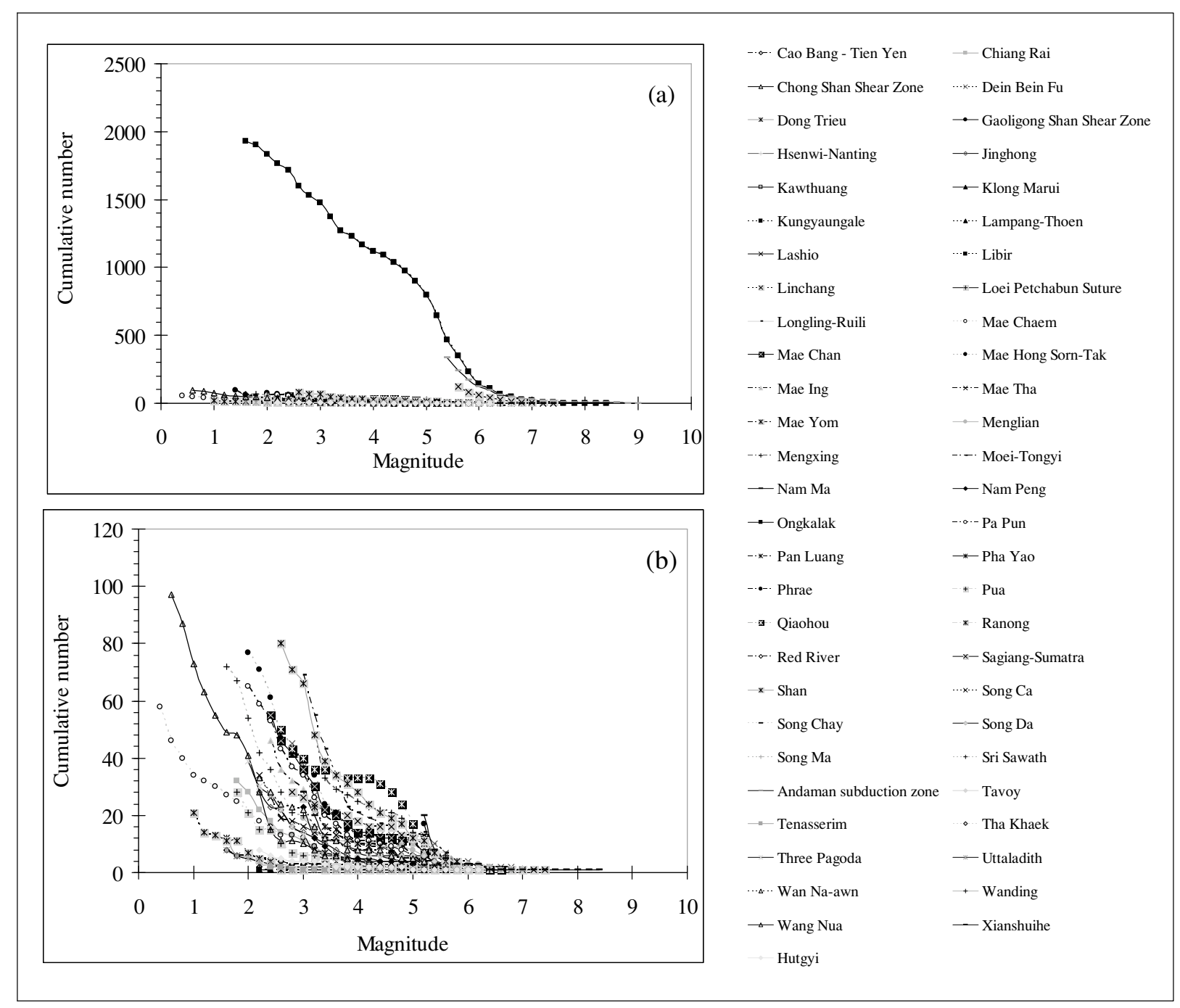

Fig. 7. Summary of the Gutenberg-Richter relationships for earthquake events within individual active fault zones identified in this study.

were less than $M_{\mathrm{w}} 6$, paleoseismological studies in some areas revealed that some earthquakes earlier than those recorded in the instrumental record time span were larger (e.g., Fenton et al., 2003; Charusiri et al., 2004; Rhodes et al., 2004; RID, 2006). Paleoseismological studies have also clearly shown that the recurrence intervals of earthquakes produced by active faulting are several hundred to several thousand years; for example, 720 years for the Kao Ka Reang fault of the Ongkalak fault zone (Charusiri, 2005), and 4,200 years for the Ton Ngoon fault of Lampang-Thoen fault zone (Charusiri et al., 2004). We concluded, therefore, that Thailand and adjacent areas may be exposed to large earthquakes with strong ground shaking, as shown by our deterministic seismic hazard map (Fig. 4). However, the DSHA also showed the seismic hazard level to be lower than our expectations in some areas, such as the Nicobar Islands and western Myanmar. Although these areas are close to the Andaman subduction zone, the DSHA showed a possible ground shaking range of $0.4-0.6 \mathrm{~g}$. We attribute this low seismic hazard to the strong ground-motion attenuation model we used for the subduction zone. The subduction zone attenuation model of Petersen et al. (2004) generated a lower seismic hazard level than the attenuation model of
Kobayashi et al. (2000) for shallow crustal (inland) earthquakes.

In our PSHA, both the exponential magnitude distribution model and the characteristic earthquake model were applied. The obtained probabilistic seismic hazard maps revealed quite similar hazard levels. No obvious evidence indicated which frequency-magnitude models are the more appropriate for this study. Therefore, probabilistic seismic hazard calculation using the logic tree weighting of both frequency-magnitude models have been performed, as shown in Fig. 8. We believe that the map derived from our DSHA (Fig. 4), in conjunction with those from our PSHA (Fig. 8), will be useful for planning and locating future structures in Thailand and adjacent areas. According to the Krinitzsky (2003) suggestion, DSHA is useful for designing critical structures, such as the nuclear power plants. However, PSHA can be applied for preliminary evaluations or for risk analysis when these are unrelated to design decisions on a critical construction.

Finally, we emphasize that the extent to which geological information contributes to seismic hazard assessment in Thailand and adjacent areas and that such assessments depend on the quantity and quality of the data collected. To 
a) $2 \%$ POE in 10 years
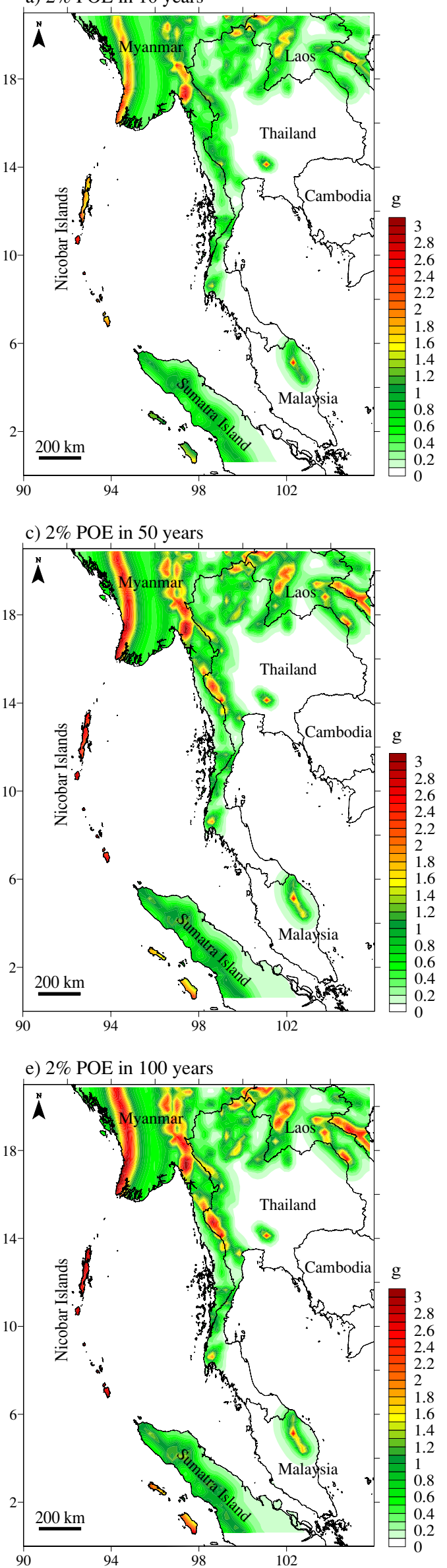

b) $10 \%$ POE in 10 years

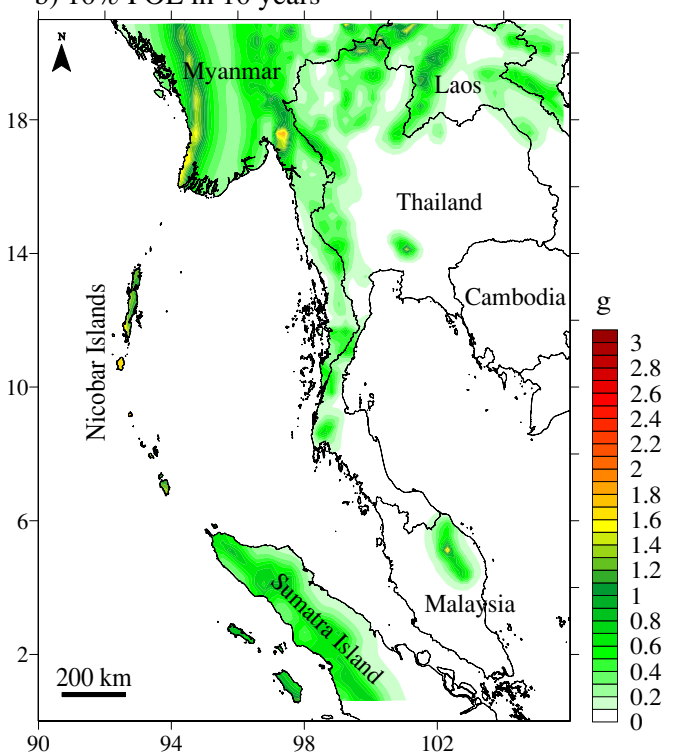

d) $10 \%$ POE in 50 years

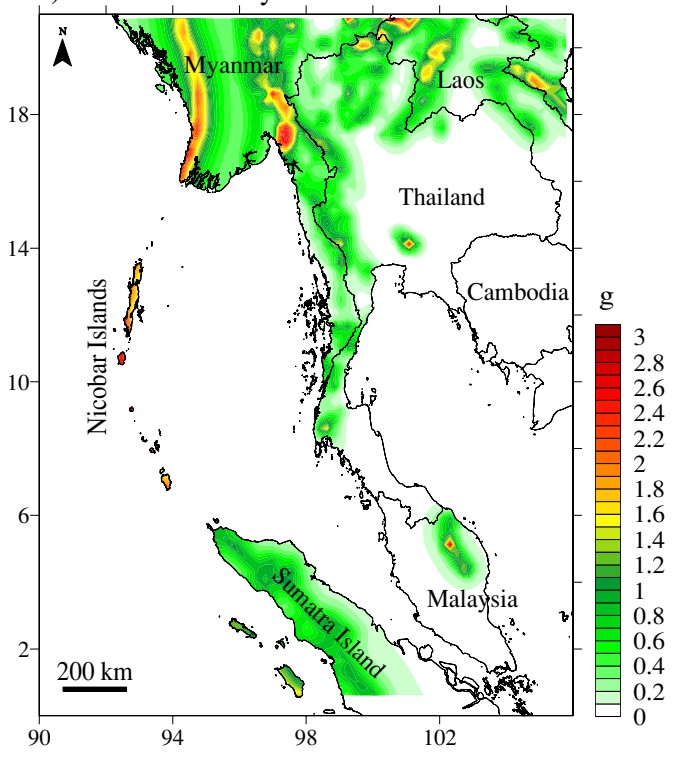

f) $10 \%$ POE in 100 years

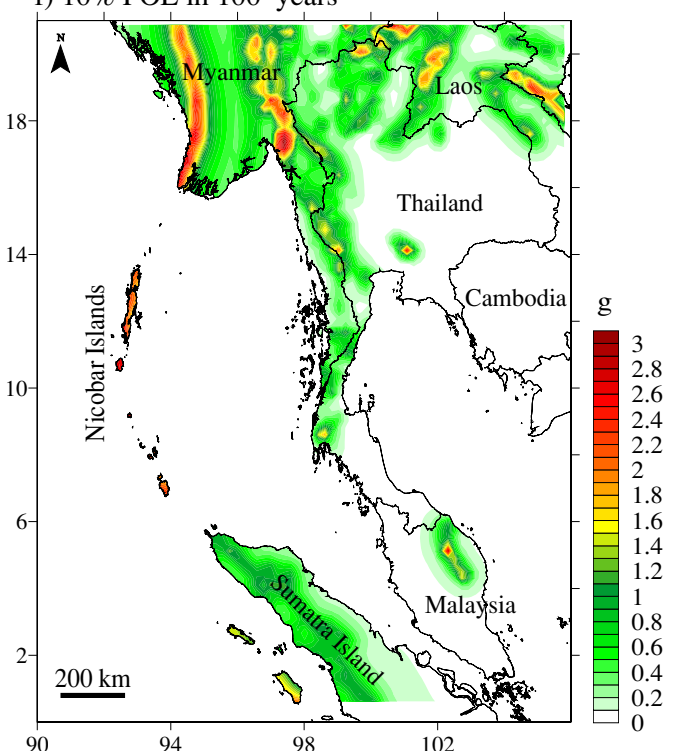

Fig. 8. Probabilistic seismic hazard maps of Thailand and adjacent areas. POE is probability of exceedance in specific time period (year). 
further refine seismic hazard analysis in this region, more detailed active fault data are indispensable. To this end, more ground motion recording stations are needed to allow the construction of a strong ground-motion attenuation model specific to Thailand and adjacent areas.

Acknowledgments. This work is sponsored by the Thailand Research Fund (Code number PHD/0093/2549) through Santi Pailoplee. The research is also supported by the Active Fault Research Center (AFRC), National Institute of Advanced Industrial Science and Technology (AIST), Japan. We thank K. Satake, M. Choowong, M. Yoshimi, and K. Yoshida for their critical reviews of the manuscript during preparation. Dr. Takashi Iidaka, editor, Dr. Nicolas Luco, and anonymous reviewers are thanked for a thorough review that greatly improved the manuscript.

\section{References}

Abrahamson, N. A. and W. J. Silva, Empirical response spectral attenuation relations for shallow crustal earthquakes, Seismol. Res. Lett., 68(1), 94-127, 1997.

Akciz, S., B. C. Burchfiel, J. L. Crowley, Y. Jiyun, and C. Liangzhong, Geometry, kinematics and regional significance of the Chong Shan shear zone, east Himalayan syntaxis, Yunnan, China, Geosphere, 4(1), 292$314,2008$.

Atakan, K., A. Ojeda, T. Camelbeeck, and M. Meghraoui, Seismic hazard analysis results for the Lower Rhine Graben and the importance of paleoseismic data, Neth. J. Geosci., 80(3-4), 305-304, 2001.

Bai, D. and M. A. Meju, Deep structure of the Longling-Ruili fault zone underneath Ruili basin near the Eastern Himalayan syntaxis: insights from magnetotelluric imaging, Tectonophysics, 364,135-146, 2003.

Bertrand, G. and C. Rangin, Tectonics of the western margin of the Shan Plateau (central Myanmar): implications for the India-Indochina oblique convergence since the Oligocene, J. Asian Earth Sci., 21, 1139_ 1157, 2003.

Boore, D. M., W. B. Joyner, and T. E. Fumal, Equations for estimating horizontal response spectra and peak acceleration from western North American earthquakes: A summary of recent work, Seismol. Res. Lett., 68(1), 128-153, 1997.

Caceres, D. and O. Kulhanek, Seismic hazard of Honduras, Nat. Hazards, 22, 49-69, 2000

Charusiri, P., Active fault study in Ongkalak fault zone, Ongkalak, Nakhon Nayok, Central Thailand, Technical report, Department of Geology, Faculty of Science, Chulalongkorn University, Bangkok, Thailand, 185 p., 2005 (in Thai with English abstract).

Charusiri, P., V. Daorerk, T. Wongvanich, S. Nakapadungrat, and S. Imsamut, Geology of the Quadrangle Economic Zone (emphasis on China and Thailand), Technical report, National Research Council of Thailand, Bangkok, Thailand, 189 p., 1999 (in Thai with English abstract).

Charusiri, P., V. Daorerk, D. Archibald, K. Hisada, and T. Ampaiwan, Geotectonic evolution of Thailand: A new synthesis, J. Geol. Soc. Thailand, 1(1-20), 1-20, 2002

Charusiri, P., V. Daorerk, M. Choowong, N. Muangnoicharoen, K. Wonin, A. Lumjuan, S. Kosuwan, P. Saithong, and P. Thonnarat, The study on the investigations of active faults in Changwat Kanchanaburi area, western Thailand, Technical report, Department of Geology, Faculty of Science, Chulalongkorn University, Bangkok, Thailand, 119 p., 2004 (in Thai with English abstract).

Convertito, V., A. Emolo, and A. Zollo, Seismic-hazard assessment for a characteristic earthquake scenario: An integrated probabilisticdeterministic method, Bull. Seismol. Soc. Am., 96(2), 377-391, 2006.

Cornell, C. A., Engineering seismic risk analysis, Bull. Seismol. Soc. Am., 58, 1583-1606, 1968.

Costa, G., G. F. Panza, P. Suhadolc, and F. Vaccari, Zoning of the Italian region with synthetic seismograms computed with known structural and source information, in Proceeding of 10th World Conference on Earthquake Engineering, Madrid, Spain, 435-438, 1992.

Costa, G., G. F. Panza, P. Suhadolc, and F. Vaccari, Zoning of the Italian territory in terms of expected peak ground acceleration derived from complete synthetic seismograms, J. Appl. Geophys., 30, 149-160, 1993.

Cuong, N. Q. and W. A. Zuchiewicz, Morphotectonic properties of the Lo River Fault near Tam Dao in North Vietnam, Nat. Hazards Earth System Sci., 1, 15-22, 2001.
Cuong, N. Q., A. Swierczewska, A. Wysocka, P. P. Dong, and V. N. Huyen, Activity of the Cao Bang-Tien Yen fault zone (NE Vietnam)-record in associated sedimentary basins, in Proceedings of 17th International Sedimentological Congress, Fukuoka, Japan, Abstracts P-074, 2006.

Department of Mineral Resources (DMR), Active fault map of Thailand, 2006 (Online Article, October 2006), http://www.dmr.go.th/ geohazard/earthquake_n/ActiveFault_Eng.htm.

Duong, C. C. and K. L. Feigl, Geodetic measurement of horizontal strain across the Red River fault near Thac Ba, Vietnam, J. Geod., 73, 298310, 1999.

Electricity Generating Authority of Thailand (EGAT), Active fault and determination of seismic parameters Hutgyi hydropower project, Technical report, Electricity Generating Authority of Thailand, Bangkok, Thailand, 89 p., 2006.

Eleftheria, P., W. Xueze, K. Vassilios, and J. Xueshen, Earthquake Triggering along the Xianshuihe fault zone of Western Sichuan, China, Pure Appl. Geophys., 161(8), 1683-1707, 2004.

Esteva, L. and R. Villaverde, Seismic risk, design spectra and structural reliability, in Proceedings of 5th World Conference on Earthquake Engineering, Rome, Italy, 2586-2597, 1973.

Fenton, C. H., P. Charusiri, and S. H. Wood, Recent paleoseismic investigations in Northern and Western Thailand, Ann. Geophys., 46(5), 957981, 2003.

Gardner, J. K. and L. Knopoff, Is the sequence of earthquakes in Southern California, with aftershocks removed, Poissonian?, Bull. Seismol. Soc. Am., 64(1), 363-367, 1974.

Gurpinar, A., The importance of paleoseismology in seismic hazard studies for critical facilities, Tectonophysics, 408, 23-28, 2005.

Gutenberg, B. and C. F. Richter, Seismicity of the Earth and Associated Phenomena, Princeton University Press, Princeton, New Jersey, 1954.

Hanks, T. C. and H. Kanamori, A moment-magnitude scale, J. Geophys. Res., 84, 2348-2350, 1979.

Howell, B. F., On the saturation of earthquake magnitudes, Bull. Seismol. Soc. Am., 71(5), 1401-1422, 1981.

Idriss, I. M., Procedures for selecting earthquake ground motions at rock sites, Technical report NIST GCR 93-625, U.S. Department of Commerce, National Institute of Standards and Technology, Gaithersburg, Maryland, 1993.

Kobayashi, S., T. Takahashi, S. Matsuzaki, M. Mori, Y. Fukushima, J. X. Zhao, and P. G. Somerville, A spectral attenuation model for Japan using digital strong motion records of JMA87 type, in Proceedings of 12th World Conference on Earthquake Engineering, Auckland, New Zealand, 2000.

Kramer, S. L., Geotechnical Earthquake Engineering, Prentice Hall, Inc. Upper Saddle River, New Jersey, 1996.

Krinitzsky, E. L., How to combine deterministic and probabilistic methods for assessing earthquake hazards, Eng. Geol., 70, 157-163, 2003.

Lacassin, R., A. Replumaz, and P. H. Leloup, Hairpin river loops and strike-slip sense inversion of Southeast Asian strike-slip faults, Geology, 26, 703-706, 1998.

Lepvrier, C., H. Maluski, V. V. Tich, and A. Leyreloup, The Early Triassic Indosinian orogeny in Vietnam (Truong Son Belt and Kontum Massif); implications for the geodynamic evolution of Indochina, Tectonophysics, 393(1-4), 87-118, 2004.

Metcalfe, I., The Bentong-Raub suture zone, J. Asian Earth Sci., 18, 691712, 2000.

Morley, C. K., Variations in Late Cenozoic-Recent strike-slip and obliqueextensional geometries, within Indochina: The influence of pre-existing fabrics, J. Struct. Geol., 29, 36-58, 2007.

Nutalaya, P., S. Sodsri, and E. P. Arnold, Series on Seismology-Volume II-Thailand, edited by E. P Arnold, in Technical report, Southeast Asia Association of Seismology and Earthquake Engineering, 402 p., 1985.

Ottemoller, L. and J. Havskov, Moment magnitude determination for local and regional earthquakes based on source spectra, Bull. Seismol. Soc. Am., 93(1), 203-214, 2003.

Palasri, C., Probabilistic seismic hazard map of Thailand, Master's thesis, Department of Civil Engineering, Faculty of Engineering, Chulalongkorn University, Bangkok, Thailand, 2006.

Paul, J., R. Burgmann, V. K. Gaur, R. Bilham, K. M. Larson, M. B. Ananda, S. Jade, M. Mukal, T. S. Anupama, G. Satyal, and D. Kumar, The motion and active deformation of India, Geophys. Res. Lett., 28 , 647-650, 2001.

Petersen, M. D., J. Dewey, S. Hartzell, C. Mueller, S. Harmsen, A D. Frankel, and K. Rukstales, Probabilistic seismic hazard analysis for Sumatra, Indonesia and across the Southern Malaysian Peninsula, Tectonophysics, 390, 141-158, 2004. 
Petersen, M. D., S. Harmsen, C. Mueller, K. Haller, J. Dewey, N. Luco, A. Crone, D. Lidke, and K. Rukstales, Documentation for the Southeast Asia Seismic Hazard Maps, Administrative Report, U.S. Department of the Interior, U.S. Geological Survey, 65 p., 2007.

Phoung, N. H., Probabilistic assessment of earthquake hazard in Vietnam based on seismotectonic regionalization, Tectonophysics, 198, 81-93, 1991.

Polachan, S., S. Pradidtan, C. Tongtaow, S. Janmaha, K. Intrawijitr, and C. Sangsuwan, Development of Cenozoic basins in Thailand, Mar. Petroleum Geol., 8, 84-97, 1991.

Rhodes, B. P., R. Perez, A. Lamjuan, and S. Kosuwan, Kinematics and tectonic implications of the Mae Kuang Fault, northern Thailand, J. Asian Earth Sci., 24(1), 79-89, 2004.

Richter, C. F., Elementary Seismology, W. H. Freeman, San Francisco, 1958.

Royal Irrigation Department (RID), Active fault investigation in Mae Yom fault zone, Kaeng Seur Ten Dam Site, Song district, Phrae Province, Thailand, Technical report, Royal Irrigation Department, Bangkok, Thailand, 175 p., 2006 (in Thai with English abstract).

Sadigh, K., C. Y. Chang, J. A. Egan, F. Makdisi, and R. R. Youngs, Attenuation relationships for shallow crustal earthquakes based on California strong motion data, Seismol. Res. Lett., 68(1), 180-189, 1997.

Saithong, P., S. Kosuwan, K. Won-in, I. Takashima, and P. Charusiri, Late Quaternary paleoseismic history and surface rupture characteristics of the Moei-Mae Ping fault zone, Tak Province, Northwestern Thailand, in International Conference on Geology, Geotechnology and Mineral Resources of Indochina, Khon Kaen, Thailand, 479-487, 2005.

Socquet, A. and M. Pubellier, Cenozoic deformation in western Yunnan (China-Myanmar border), J. Asian Earth Sci., 24, 495-515, 2005.

Songmuang, R., P. Charusiri, M. Choowong, K. Won-In, I. Takashima, and S. Kosuwan, Detecting active faults using remote-sensing technique: A case study in the Sri Sawat Area, western Thailand, Sci. Asia, 33, 23-33, 2007.

Takemoto, K., N. Halim, Y. Otofuji, V. T. Tran, V. D. Le, and S. Hada, New paleomagnetic constraints on the extrusion of Indochina: Late Cretaceous results from the Song Da terrane, northern Vietnam, Earth Planet. Sci. Lett., 229, 273-285, 2005.

Warnitchai, P. and A. Lisantono, Probabilistic seismic risk mapping for Thailand, Proceedings of 11th World Conference on Earthquake Engineering, Acapulco, Mexico, 1996.

Wells, D. L. and K. J. Coppersmith, Updated empirical relationships among magnitude, rupture length, rupture area, and surface displacement, Bull. Seismol. Soc. Am., 84, 974-1002, 1994.

Wiemer, S., A software package to analyze seismicity: ZMAP, Seismol. Res., 72, 373-382, 2001.

Wong, I., C. Fenton, M. Dober, J. Zachariasen, and F. Terra, Seismic hazard evaluation of the Tha Sae project, Thailand, Technical report, Punya Consultants Co. Ltd., 118 p., 2005.

Youngs, R. R. and K. J. Coppersmith, Implications of fault slip rates and earthquake recurrence models to probabilistic seismic hazard estimates, Bull. Seismol. Soc. Am., 75, 939-964, 1985.

Youngs, R. R., S. J. Chiou, W. J. Silva, and J. R. Humphrey, Strong ground motion attenuation relationships for subduction zone earthquakes, Seismol. Res. Lett., 68, 58-73, 1997.

Zuchiewicz, W., N. Q. Cuong, A. Bluszcz, and M. Michalik, Quaternary sediments in the Dien Bien Phu fault zone, NW Vietnam: a record of young tectonic processes in the light of OSL-SAR dating results, Geomorphology, 60, 269-302, 2004.

S. Pailoplee (e-mail: pailoplee.s@gmail.com), Y. Sugiyama, and P. Charusiri 